\title{
Endovascular Stroke Treatment of Nonagenarians
}

\author{
(D) M. Möhlenbruch, (D). Pfaff, (DS. Schönenberger, (DS. Nagel, (D). Bösel, DC. Herweh, (DP. Ringleb, (D). Bendszus, and (DS. Stampfl
}

\section{ABSTRACT}

BACKGROUND AND PURPOSE: Although endovascular treatment has become a standard therapy in patients with acute stroke, the benefit for very old patients remains uncertain. The purpose of this study was the evaluation of procedural and outcome data of patients $\geq 90$ years undergoing endovascular stroke treatment.

MATERIALS AND METHODS: We retrospectively analyzed prospectively collected data of patients $\geq 90$ years in whom endovascular stroke treatment was performed between January 2011 and January 2016. Recanalization was assessed according to the TICI score. The clinical condition was evaluated on admission (NIHSS, prestroke mRS), at discharge (NIHSS), and after 3 months (mRS).

RESULTS: Twenty-nine patients met the inclusion criteria for this analysis. The median prestroke mRS was 2 . Successful recanalization $(\mathrm{TICl} \geq 2 \mathrm{~b})$ was achieved in 22 patients (75.9\%). In 9 patients, an NIHSS improvement $\geq 10$ points was noted between admission and discharge. After 3 months, $17.2 \%$ of the patients had an mRS of $0-2$ or exhibited prestroke mRS, and $24.1 \%$ achieved mRS $0-3$. Mortality rate was $44.8 \%$. There was only 1 minor procedure-related complication (small SAH without clinical sequelae).

CONCLUSIONS: Despite high mortality rates and only moderate overall outcome, $17.2 \%$ of the patients achieved mRS $0-2$ or prestroke $\mathrm{mRS}$, and no serious procedure-related complications occurred. Therefore, very high age should not per se be an exclusion criterion for endovascular stroke treatment.

I

t is expected that the elderly population will grow substantially over the next few decades, with a doubling of the percentage of people over 80 years in the United States as well as in the European Union by 2050. ${ }^{1,2}$ The risk of stroke, a leading cause of disability and death, increases with age, ${ }^{3}$ and patients older than 80 years have the highest incidence. ${ }^{4}$

In studies assessing the outcomes of patients with stroke after endovascular treatment, patients are frequently separated into groups $<80$ years versus $\geq 80$ years. Age greater than 80 years was found to be associated with a poorer clinical outcome and increased mortality, ${ }^{5}$ though revascularization success rates were comparable with those of younger patients. ${ }^{6}$ However, recent large prospective trials on endovascular stroke treatment had no upper age limit, ${ }^{7,8}$ and the subgroup analysis in the Multicenter Randomized Clinical Trial of Endovascular Treatment for Acute Ischemic Stroke in the

Received May 24, 2016; accepted after revision August 19.

From the Departments of Neuroradiology (M.M., J.P., C.H., M.B., S. Stampfl) and Neurology (S. Schönenberger, S.N., J.B., P.R.), University Hospital Heidelberg, Heidelberg, Germany.

Please address correspondence to Sibylle Stampfl, MD, Department of Neuroradiology, University Hospital Heidelberg, Im Neuenheimer Feld 400, 69120 Heidelberg, Germany; e-mail: sibylle.stampfl@med.uni-heidelberg.de

http://dx.doi.org/10.3174/ajnr.A4976
Netherlands (MR CLEAN) trial showed a treatment effect in all predefined subgroups, including the subgroup based on age ( $<80$ years versus $\geq 80$ years). Therefore, patients $\geq 80$ years regularly undergo endovascular stroke treatment in our institution if they are eligible. Increasingly, we also treat nonagenarians (patients $\geq 90$ years), though in the literature, most reports on the older age group include patients between 80 and 90 years, and only few data on patients older than 90 years exist. The oldest documented patient who underwent endovascular stroke treatment was a 103 -year-old woman ${ }^{9}$ who recovered well.

In this study, we summarize our experience of endovascular stroke treatment in patients $\geq 90$ years of age between January 2011 and January 2016.

\section{MATERIALS AND METHODS Patient Selection}

Approval for collection of interventional and clinical data was given by the local ethics committee.

We retrospectively analyzed prospectively collected data of patients with acute stroke who were treated between January 2011 and January 2016. They met the following inclusion criteria: age $\geq 90$ years, reasonable cognitive and functional prestroke status (no advanced dementia, only mild to moderate disabilities), no signs of 


\begin{tabular}{|c|c|}
\hline \multicolumn{2}{|l|}{ Demographics } \\
\hline Mean age, yr (range) & $91.9(90-99)$ \\
\hline $\operatorname{Sex}(F / M)$ & $19 / 10$ \\
\hline \multicolumn{2}{|l|}{ Medical history, No. of patients } \\
\hline Hypertension & 25 \\
\hline Atrial fibrillation & 20 \\
\hline Diabetes mellitus & 7 \\
\hline Coronary artery disease & 5 ( $n=1$ status after myocardial infarction) \\
\hline Cardiac insufficiency & 8 \\
\hline Peripheral artery disease & 3 ( $n=2$ with femoropopliteal bypass surgery) \\
\hline Previous stroke & $\begin{array}{l}8 \text { (lacunar ischemia or partial MCA, PCA, or PICA } \\
\text { infarction with good recovery; transient } \\
\text { ischemic attack, } n=1 \text { ) }\end{array}$ \\
\hline Renal insufficiency & 9 \\
\hline History of cancer & 3 (multiple myeloma, breast cancer, basalioma) \\
\hline Coxarthrosis & 5 (state after hip fracture, $n=1$ ) \\
\hline \multicolumn{2}{|l|}{ Clinical presentation and outcome } \\
\hline Prestroke mRS, median (IQR) & $2(1-3)$ \\
\hline Initial NIHSS, median (IQR) & $20(16.5-22.5)$ \\
\hline $\begin{array}{l}\text { mRS of surviving patients at } 90 \text { days, } \\
\text { median (IQR) }\end{array}$ & $4(2.25-5)$ \\
\hline Mortality, No. of patients (\%) & $13(44.8)$ \\
\hline \multicolumn{2}{|l|}{ Occlusion site, No. of patients (\%) } \\
\hline ICA terminus & $4(13.8)$ \\
\hline ICA/MCA & $5(17.2)$ \\
\hline M1 segment & $12(41.4)$ \\
\hline M2 segment & $4(13.8)$ \\
\hline Vertebrobasilar & $4(13.8)$ \\
\hline \multicolumn{2}{|l|}{$\begin{array}{l}\text { Angiographic outcome, No. of } \\
\text { patients (\%) }\end{array}$} \\
\hline $\mathrm{TICl} 0$ & $4(13.8)$ \\
\hline $\mathrm{TICl} 1$ & $0(0)$ \\
\hline $\mathrm{TICl} 2 \mathrm{a}$ & $3(10.3)$ \\
\hline $\mathrm{TICl} 2 \mathrm{~b}$ & $12(41.4)$ \\
\hline $\mathrm{TICl} 3$ & $10(34.5)$ \\
\hline
\end{tabular}

Note:- IQR indicates interquartile range; PCA, posterior cerebral artery.

major infarction (>one-third of the MCA territory) on baseline CT or MR imaging, and CTA- or MRA-proved major intracranial vessel occlusion.

\section{Interventional Procedure}

All procedures were performed under general anesthesia or conscious sedation. As vascular access, an $8 \mathrm{~F}$ sheath was placed in the right femoral artery. Then, an $8 \mathrm{~F}$ catheter was advanced into the common carotid artery of the occluded side. In patients with occlusion of the posterior circulation, a long 7F sheath was placed in the right femoral artery with the tip of the sheath in the subclavian artery. Subsequently, a 5F Sofia catheter (MicroVention, Tustin, California) or a 5F Neuron catheter (Penumbra, Alameda, California) was positioned within the ICA close to the thrombus. The microcatheter tip was placed distal to the thrombus, and the stent-retriever device was advanced through the microcatheter. Then, a stent-retriever device (Solitaire [Covidien, Irvine, California]; Trevo [Stryker, Kalamazoo, Michigan]) was deployed by pulling back the microcatheter. Angiographic runs were performed to control flow restoration. Device and microcatheter were simultaneously pulled back under continuous aspiration through the intermediate catheter, which was applied by using a $20-$ to $60-\mathrm{mL}$ syringe. Again, angiographic runs were performed to document the result. If no sufficient recanalization was achieved, thrombectomy was repeated.
Evaluation of Angiographic Data

Successful recanalization was defined as TICI (Thrombolysis in Cerebral Infarction) score $2 \mathrm{~b} / 3 .{ }^{10}$ Angiographic images were evaluated in consensus by 2 neuroradiologists (S.Stampfl, M.M.) regarding the following aspects: site of occlusion, time to interventional treatment (symptom onset to first angiographic image), time to revascularization (time between the first and the final angiographic image), pre- and postprocedural TICI, and procedure-related complications. Furthermore, it was noted if IV rtPA was administered.

\section{Evaluation of Outcome Data}

Follow-up CT was performed after 24-36 hours or earlier in case of clinical deterioration. All patients were treated on a specialized neuro-intensive care unit or a certified stroke unit. NIHSS was used to quantify neurologic deficit; here, we analyzed admission and discharge NIHSS. After 90 days, the mRS was assessed by a semistandardized telephone interview or during an outpatient visit by a trained investigator not blinded to the type of treatment. Favorable clinical outcome was defined as mRS $0-2$ or achieving prestroke $\mathrm{mRS}$ at 3 months.

Intracranial hemorrhage was classified according to the second EuropeanAustralasian Acute Stroke Study classification. ${ }^{11}$

\section{Statistics}

All data were collected in a data base. Continuous data are described by median and interquartile range or mean and standard deviation. Statistical analysis was performed by using GraphPad Prism 5.0 (GraphPad Software, San Diego, California).

\section{RESULTS}

\section{Patient Selection}

The Table gives an overview of baseline characteristics and angiographic and clinical data.

Overall, 29 nonagenarians from a cohort of 615 patients with interventional stroke treatment underwent endovascular treatment for acute stroke between January 2011 and January 2016. Mean age was 91.9 years (range, 90-99 years; 19 women, 10 men). In 12 patients, time of symptom onset remained uncertain. In the other patients, the median time of symptom onset to time of the first image was 206 minutes (range, 91-321 minutes). Four patients presented with basilar artery occlusions. The other patients had occlusions of the anterior circulation (ICA terminus, $n=4$; ICA terminus + MCA, $n=5$; M1 segment, $n=12$; M2 segment $n=4)$.

In 17 patients, additional IV rtPA was administered as part of 
the bridging concept combining IV thrombolysis $(0.9 \mathrm{mg} / \mathrm{kg}$ body weight, with $10 \%$ administered as a bolus) and endovascular therapy.

The median prestroke mRS was 2 (range, $0-4$; interquartile range, 1-3). Three patients presented with a prestroke mRS of 4 mainly because of orthopedic diseases, but they had a good prestroke cognitive function, or the prestroke mRS was uncertain at admission.

Most patients had a history of hypertension $(n=25)$ and atrial fibrillation $(n=20)$. Eight patients had a history of stroke (lacunar ischemia, $n=3$; partial MCA infarction, $n=2$; partial posterior cerebral artery infarction, $n=1$; partial PICA infarction, $n=$ 2 ), but they had recovered well with only minor disabilities remaining. One patient had a history of multiple myeloma (classified as stable). One patient had a history of basalioma. Another patient underwent breast cancer treatment in the 1980s.

Median NIHSS at admission was 20 (interquartile range, 16.5-22.5).

\section{Evaluation of Angiographic Data}

Before the procedure, TICI was 0 in all patients. In 22 patients (75.9\%), recanalization was successful (TICI $2 \mathrm{~b}, n=12$; TICI 3 , $n=10$ ). In 4 patients (basilar artery occlusion, $n=1$; ICA occlusion, $n=1$; M1 occlusion, $n=2$ ), the procedure was futile (no stable guide-catheter position because of extensive vessel elongation and kinking, $n=3$; no passage of the occluded ICA lumen possible, $n=1$ ). In the other patients, the final recanalization result was achieved 77 minutes after groin puncture (median; range, 19-142 minutes).

In 2 patients who were treated in 2011, permanent Solitaire stent implantation in the MCA was performed to maintain sufficient revascularization. In these patients, tirofiban was administered for 24 hours (overlapping with aspirin and clopidogrel). In 1 patient with high-grade ICA stenosis, additional carotid stent implantation was necessary to access the intracranial lesion. This patient received a loading dose of aspirin and $2000 \mathrm{IU}$ heparin.

\section{Evaluation of Outcome Data}

Nine patients (31\%) improved $\geq 10$ NIHSS points between admission and discharge. After 90 days, the mortality rate was $44.8 \%$ (13 patients). In 9 of these patients, life-prolonging care was withdrawn because of advance directives or because of the presumed wishes of the patient. All patients died because of the infarction extent or non-neurologic stroke-related complications such as pneumonia.

The median mRS of the surviving patients was 4 (interquartile range, 2.25-5). Favorable clinical outcome (mRS 0-2) or prestroke $\mathrm{mRS}$ was regained in $17.2 \%$ of the patients (mRS $0-2, n=$ 4 [13.8\%]; mRS 3, $n=3$ [10.3\%]; mRS $4-5, n=9$ [31\%]).

\section{Complications}

In 1 patient, vessel perforation with subsequent small SAH occurred during thrombectomy. However, this did not increase morbidity, and the patient presented with a mRS of 3 after 90 days (prestroke mRS was also 3).

Intraparenchymal hemorrhage occurred as follows: HI1 (small petechiae), $n=1$; HI 2 (confluent petechiae), $n=1$; PH 1
$(<30 \%$ of the infarcted area, with some mild space-occupying effect), $n=3$. Permanent ICA or MCA stent implantation had not been performed in any of these patients.

\section{DISCUSSION}

Safety and efficacy of endovascular stroke therapy has been proved in several trials. ${ }^{7,8}$ Accordingly, an increasing number of elderly patients with stroke undergo recanalization procedures. In this study, we report our experience with endovascular stroke therapy in nonagenarians. To our knowledge, this is the first report on endovascular treatment of a larger patient cohort in this age group. The outcome of our study patients is limited, with a mortality rate of $44.8 \%$ and a median mRS of 4 in the surviving patients after 3 months. However, interpreting these results, we have to consider several facts. First of all, it is known that the higher incidence of prestroke comorbidity and poststroke nonneurologic complications such as pneumonia lead to a higher poststroke mortality and disability in elderly patients with stroke. ${ }^{6,12-15}$ Singer et al ${ }^{16}$ reported a highly age-related clinical outcome: in the lowest age quartile ( $<56$ years), $60 \%$ experienced a favorable outcome, contrary to $17 \%$ in the highest age quartile ( $>77$ years). Prestroke mRS of elderly patients with stroke is usually worse compared with younger patients and mainly contributes to the limited outcome. In a single-center study, approximately one-third of the elderly ( $>80$ years) patients with stroke treated with intra-arterial therapy had a baseline mRS $>1$, and $59 \%$ had died after 3 months. ${ }^{17}$ In another study, prestroke mRS was $3-4$ in $13 \%$ of the patients, ${ }^{18}$ with a mortality rate of $48 \%$ at 3 months. Similarly, only in a minority of our study patients was the prestroke mRS 0 or 1 . Restoring the prestroke condition is the best achievable result in most patients. Although this could be obtained in only $17.2 \%$ of our study patients, an NIHSS improvement $\geq 10$ points between admission and discharge was observed in $31 \%$. Furthermore, in $24 \%$ of our patients, mRS of $0-3$ was achieved, which seems an acceptable result in our aged study population. This should be taken into account because without therapy, outcome of patients with stroke in the 10th decade of life is probably even worse. In a publication from 1999 evaluating the natural course of stroke, it was described that in the older age group ( $>80$ years), $45 \%$ of the patients had a prestroke mRS of $2-5$, and the mortality rate was $44.6 \%$ after 3 months, ${ }^{19}$ which is almost identical to the mortality rate in our study. However, patients in our study are at least 10 years older with a presumably worse prognosis.

It has been discussed that the greater likelihood of withdrawing life-prolonging care because of advance directives or presumed wishes of the patient contributes to the higher mortality rate in very old patients. ${ }^{17}$ Life-prolonging care was withdrawn in most patients in our study who died. However, the possible outcome without care withdrawal is unknown and, of course, the prognosis in these patients was dismal.

As a consequence of the reported worse outcome of elderly patients with stroke, some prospective trials included only patients younger than 80 years $^{20}$ or 85 years. ${ }^{21,22}$

In contrast, a recently published report found that endovascular therapy improved the outcome and reduced the risk of hospital-acquired infections in patients $\geq 80$ years with acute stroke. ${ }^{23}$ In most of the recent large randomized trials, there was no upper 
age limit, ${ }^{7,8,24}$ and the oldest patient in the MR CLEAN trial was 96 years old. ${ }^{7}$ A subgroup analysis of the MR CLEAN trial showed a treatment effect in all subgroups, including the one based on age. ${ }^{7}$ In fact, endovascular treatment was even more beneficial for elderly patients with stroke.

Correspondingly, a subgroup analysis of the Endovascular Treatment for Small Core and Proximal Occlusion Ischemic Stroke (ESCAPE) trial ${ }^{24}$ documented a benefit in the endovascular treatment group even in elderly patients.

In these subgroup analyses as well as in other studies, ${ }^{6,25} \mathrm{pa-}$ tients were separated into groups $<80$ years versus $\geq 80$ years. However, with endovascular stroke therapy emerging, neurointerventionalists are increasingly faced with the question of whether to offer this treatment even to nonagenarians. It always remains an individual decision and should depend on the patient's prestroke cognitive and functional condition in addition to the regularly used clinical and imaging criteria. In our study, the decision for endovascular treatment was always based on the consensus of an interdisciplinary stroke team, and not only the prestroke disability, but also the prestroke cognitive function was taken into account. Therefore, in some cases, even patients with a moderately severe disability (corresponding to mRS 4) were treated because they participated in life despite their physical handicap or because prestroke mRS was uncertain at admission. However, we have to admit that the 3 patients with prestroke mRS 4 had a bad outcome (mRS $5, n=1$; mRS $6, n=2$ ), and it remains controversial if such patients should be treated in the future.

Endovascular stroke therapy in elderly patients is potentially more complicated because of age-related vessel elongation and calcification, and these difficult vascular access conditions might result in lower success rates. Indeed, vascular access was not possible in $13.8 \%$ of our patients (compared with approximately $4 \%-5 \%$ as reported in the literature ${ }^{26,27}$ ) and, accordingly, thrombectomy could not be performed. Importantly, the failed attempts were not associated with complications. During decision-making, one should also keep in mind that the complication rate of endovascular stroke therapy is low, and the possible advantages outweigh the risks.

Our study has several limitations. First of all, it is a retrospective single-center analysis; the number of patients is relatively small, and the study group is heterogeneous (inclusion of patients with occlusion in the anterior as well as in the posterior circulation). However, to our knowledge, there is no other report about a series of patients with stroke in this age group treated with thrombectomy.

Another limitation is that we do not have a control group of elderly patients with stroke who were not treated with thrombectomy or received IV lysis alone.

Furthermore, in elderly patients, the cognitive dimension is at least as important as disability. However, the cognitive function was not evaluated in our study.

\section{CONCLUSIONS}

The aged population in this study had a high mortality with an overall limited outcome after 3 months. Furthermore, the vascular approach is more complicated in the elderly population, and the revascularization rates achieved are slightly lower. However, increased age did not seem to be associated with higher procedural complication rates. Almost every fifth carefully selected pa- tient achieved a good clinical result (mRS 0-2 or restoration of prestroke $\mathrm{mRS}$ ). Hence, thrombectomy should not be withheld from nonagenarians. Exclusion of patients from endovascular treatment on the basis of age alone doesn't seem to be justified.

Disclosures: Markus Möhlenbruch—UNRELATED: Board Membership: Codman; Consultancy: Acandis, Codman, MicroVention, Phenox; Payment for Lectures (including service on Speakers Bureaus): Codman, MicroVention, Phenox. Johannes Pfaff-UNRELATED: Grants/Grants Pending: Siemens Healthineers*; Payment for Lectures (including service on Speakers Bureaus): Siemens Healthineers, Comments: payment for lectures during the Deutsche Röntgenkongress 2015 (German X-Ray Congress); Travel/Accommodations/Meeting Expenses Unrelated to Activities Listed: Stryker Neurovascular, Comments: annual meeting of the Deutsche Gesellschaft für Neuroradiologie 2015 (German Society for Neuroradiology). Simon Nagel-UNRELATED: Consultancy: Brainomix; Payment for Lectures (including service on Speakers Bureaus): Bayer, Pfizer, Medtronic; Travel/Accommodations/ Meeting Expenses Unrelated to Activities Listed: Böhringer Ingelheim. Julian BöselUNRELATED: Payment for Lectures (including service on Speakers Bureaus): Bard, Zoll, Seiratherm, Sedana, Comments: speaker honoraria; Travel/Accommodations/ Meeting Expenses Unrelated to Activities Listed: Bard, Zoll, Seiratherm, Sedana, Comments: travel support. Peter Ringleb_UNRELATED: Consultancy: Boehringer Ingelheim, Covidien*; Payment for Lectures (including service on Speakers Bureaus): Boehringer Ingelheim, Bayer, BMS, Pfizer, Daichii Sankyo*; Travel/Accommodations/Meeting Expenses Unrelated to Activities Listed: Boehringer Ingelheim, Bayer, Pfizer.* Martin Bendszus_UNRELATED: Board Membership: DSMB Vascular Dynamics; Consultancy: Roche, Guerbet, Codman; Grants/Grants Pending: DFG, Hopp Foundation, Novartis, Siemens, Guerbet, Stryker, Covidien*; Payment for Lectures (including service on Speakers Bureaus): Novartis, Roche, Guerbet, Teva, Bayer, Codman. *Money paid to the institution.

\section{REFERENCES}

1. Vincent GK, Velkoff VA. The next four decades. The older population in the United States: 2010-50. Population estimates and projections. https://www.census.gov/prod/2010pubs/p25-1138.pdf. Accessed April 1, 2016

2. Population projections 2004-2050. EU25 population rises until 2025, then falls. Eurostat news release 48/2005; April 8, 2005. http://ec. europa.eu/eurostat/web/products-press-releases/-/3-08042005-AP. Accessed October 3, 2016

3. Wolf PA, D'Agostino RB, Belanger AJ, et al. Probability of stroke: a risk profile from the Framingham Study. Stroke 1991;22:312-18 CrossRef Medline

4. Mozaffarian D, Benjamin EJ, Go AS, et al. Heart disease and stroke statistics-2015 update: a report from the American Heart Association. Circulation 2015;27 131:e29-322 CrossRef Medline

5. Villwock MR, Singla A, Padalino DJ, et al. Acute ischaemic stroke outcomes following mechanical thrombectomy in the elderly versus their younger counterpart: a retrospective cohort study. $B M J$ Open 2014;4:e004480 CrossRef Medline

6. Castonguay AC, Zaidat OO, Novakovic R, et al. Influence of age on clinical and revascularization outcomes in the North American Solitaire Stent-Retriever Acute Stroke Registry. Stroke 2014;45:3631-36 CrossRef Medline

7. Berkhemer OA, Fransen PS, Beumer D, et al. A randomized trial of intraarterial treatment for acute ischemic stroke. NEngl J Med 2015; 372:11-20 CrossRef Medline

8. Campbell BC, Mitchell PJ, Kleinig TJ, et al. Endovascular therapy for ischemic stroke with perfusion-imaging selection. $N$ Engl J Med 2015;372;1009-18 CrossRef Medline

9. Boo S, Duru UB, Smith MS, et al. Successful endovascular stroke therapy in a 103-year-old woman. J Neurointerv Surg 2015 Nov 9. [Epub ahead of print] CrossRef Medline

10. Higashida RT, Furlan AJ, Roberts $\mathrm{H}$, et al. Trial design and reporting standards for intra-arterial cerebral thrombolysis for acute ischemic stroke. Stroke 2003;34:e109-37 CrossRef Medline

11. Hacke W, Kaste M, Fieschi C, et al. Randomised double-blind placebo-controlled trial of thrombolytic therapy with intravenous alteplase in acute ischaemic stroke (ECASS II). Second European- 
Australasian Acute Stroke Study Investigators. Lancet 1998;352: 1245-51 CrossRef Medline

12. Qureshi AI, Suri MF, Georgiadis AL, et al. Intra-arterial recanalization techniques for patients $\mathbf{8 0}$ years or older with acute ischemic stroke: pooled analysis from 4 prospective studies. AJNR Am J Neuroradiol 2009;30:1184-89 CrossRef Medline

13. Broussalis E, Weymayr F, Hitzl W, et al. Endovascular mechanical recanalization of acute ischaemic stroke in octogenarians. Eur Radiol 2016;26:1742-50 CrossRef Medline

14. Sharma JC, Fletcher S, Vassallo M. Strokes in the elderly-higher acute and 3-month mortality-an explanation. Cerebrovasc Dis 1999;9:2-9 CrossRef

15. Denti L, Scoditti U, Tonelli C, et al. The poor outcome of ischemic stroke in very old people: a cohort study of its determinants. $\mathrm{J} \mathrm{Am}$ Geriatr Soc 2010;58:12-17 CrossRef Medline

16. Singer OC, Haring HP, Trenkler J, et al. Age dependency of successful recanalization in anterior circulation stroke: the ENDOSTROKE study. Cerebrovasc Dis 2013;36:437-45 CrossRef Medline

17. Chandra RV, Leslie-Mazwi TM, Oh DC, et al. Elderly patients are at higher risk for poor outcomes after intra-arterial therapy. Stroke 2012;43:2356-61 CrossRef Medline

18. Kurre W, Aguilar-Pérez M, Niehaus L, et al. Predictors of outcome after mechanical thrombectomy for anterior circulation large vessel occlusion in patients aged $\geq \mathbf{8 0}$ years. Cerebrovasc Dis 2013;36: 430-36 CrossRef Medline

19. Di Carlo A, Lamassa M, Pracucci G, et al. Stroke in the very old: clinical presentation and determinants of 3-month functional outcome: a European perspective. European BIOMED Study of Stroke Care Group. Stroke 1999;30:2313-19 CrossRef Medline

20. Jovin TG, Chamorro A, Cobo E, et al. Thrombectomy within $\mathbf{8}$ hours after symptom onset in ischemic stroke. N Engl J Med 2015;372: 2296-306 CrossRef Medline

21. Saver JL, Goyal M, Bonafe A, et al. Stent-retriever thrombectomy after intravenous t-PA vs. t-PA alone in stroke. N Engl J Med 2015; 372:2285-95 CrossRef Medline

22. Jansen O, Macho JM, Killer-Oberpfalzer M, et al. Neurothrombectomy for the treatment of acute ischemic stroke: results from the TREVO study. Cerebrovasc Dis 2013;36:218-25 CrossRef Medline

23. Hwang K, Hwang G, Kwon OK, et al. Endovascular treatment for acute ischemic stroke patients over $\mathbf{8 0}$ years of age. J Cerebrovasc Endovasc Neurosurg 2015;17:173-79 CrossRef Medline

24. Goyal M, Demchuk AM, Menon BK, et al. Randomized assessment of rapid endovascular treatment of ischemic stroke. $N$ Engl J Med 2015;372:1019-30 CrossRef Medline

25. To CY, Rajamand S, Mehra R, et al. Outcome of mechanical thrombectomy in the very elderly for the treatment of acute ischemic stroke: the real world experience. Acta Radiol Open 2015;4: 2058460115599423 CrossRef Medline

26. Wiesmann M, Kalder J, Reich A, et al. Feasibility of combined surgical and endovascular carotid access for interventional treatment of ischemic stroke. J Neurointervent Surg 2016;8:571-75 CrossRef Medline

27. Ribo M, Flores A, Rubiera M, et al. Difficult catheter access to the occluded vessel during endovascular treatment of acute ischemic stroke is associated with worse clinical outcome. J Neurointervent Surg 2013;5(suppl 1):i70-73 CrossRef Medline 